\title{
INFÂNCIAS E EDUCAÇÃO GUARANI
}

\author{
Tamiris Zinn ${ }^{1}$ \\ Sandra Regina Simonis Richter ${ }^{2}$ \\ Ana Luisa Teixeira de Menezes ${ }^{3}$
}

\section{RESUMO}

Os projetos Infância e Educação Guarani e Dimensão poética das linguagens na educação da infância, ambos vinculados ao grupo de pesquisa LinCE - Linguagens, Cultura $e$ Educação, estabelecem interlocução entre pesquisadores, acadêmicos e escolas indígenas para pesquisar a educação das crianças Guarani em duas aldeias no interior do Rio Grande do Sul. O objetivo é promover abertura a outros modos de interrogar a educação das crianças em contextos coletivos a partir da interlocução entre princípio biocêntrico, pensamento ameríndio e as fenomenologias da imaginação poética, do corpo operante no mundo e da ação narrativa. Para problematizar a submissão das crianças pequenas à forma escolar dominante e avançar no processo dialógico de formação das escolas diferenciadas Guarani, a abordagem metodológica sustenta-se na etnografia e na pesquisa-ação com os índios Guarani nas aldeias de Estrela Velha e Salto do Jacuí. Os encontros permitem compreender valores educacionais sustentados em uma estética e uma ética dos tempos lentos e contínuos, do corpo no mundo, do imagético multisensório, do poder das narrativas míticas que revelam modos plurais de conceber a ideia de infância e a coexistência entre adultos e crianças.

Palavras-chave: Educação Guarani. Infâncias. Criança. Escola diferenciada. Linguagem.

\begin{abstract}
The projects of Childhood and the Guarani Education and Poetic dimension of languages in childhood education, both linked to the research group LinCE - Languages, Culture and Education in its Portuguese acronym, establish interlocution among researchers, scholars and indigenous schools to research the education of the Guarani children in two villages in the countryside of Rio Grande do Sul. The objective is promote the opening to new methods to interrogate the education of the children in collective contexts from the interlocution among biocentric principle, Amerindian thoughts and the phenomenology of poetic imagination, of the operating body in the world and the narrative action. To problematize the submission of the small children to the dominating's school way and to advance in the formation dialogic process of the differentiated Guarani schools, the methodological approach sustains itself in the ethnography and in the research-action with the Guarani Indians in the villages of Estrela Velha and Salto do Jacuí. The meetings allow to comprehend educational values sustained in an aesthetic and an ethic of the slower times, of the body in the world, of the multisensory imagery, of the power of the mythical narratives that reveal plural methods to conceive the idea of infancy and the coexistence between adults and children.
\end{abstract}

Keywords: Guarani Education. Childhood. Child. Differentiated School. Language.

\footnotetext{
${ }^{1}$ Aluna do Curso de Pedagogia da Universidade de Santa Cruz do Sul - UNISC. <tamiriszinn@yahoo.com.br>

2 Professora do Departamento de Educação na Universidade de Santa Cruz do Sul - UNISC. <srichter@unisc.br>

${ }^{3}$ Professora do Departamento de Psicologia na Universidade de Santa Cruz do Sul - UNISC. <luisa@unisc.br>
} 


\section{INTRODUÇÃO}

A educação das crianças pequenas em contextos de vida coletivos na cidade ou no campo e a educação das crianças indígenas em escolas diferenciadas nas aldeias Guarani configuram temas pouco debatidos na pesquisa educacional, apresentando discussões teóricometodológicas ainda incipientes. Tanto a educação de crianças pequenas quanto a educação nas aldeias indígenas são pautas recentes na política educacional brasileira, pois surgem como responsabilidade dos Sistemas Educacionais Públicos apenas na última década do século XX. Através do Decreto Presidencial n ${ }^{o}$ 26/1991 foi atribuído ao Ministério da Educação a competência para coordenar as ações referentes à educação indígena no Brasil, bem como a Lei de Diretrizes e Bases da Educação Nacional n 9394/96 que assume a Educação Infantil (Creche e Pré-Escola) como primeira etapa da Educação Básica. A aproximação que realizamos entre esses dois campos emergentes de políticas educacionais, de pesquisa acadêmica e de reflexão pedagógica no país pretende destacar a relevância da reunião de esforços entre estudos e investigações que contribuam para tencionar os debates em torno da submissão das crianças à "forma escolar" (VICENT; LAHIRE; THIN, 2001) propondo outros caminhos, outra sensibilidade para com a experiência da infância no plural.

Nessa intenção, aproximamos nossas trajetórias de iniciação científica e de pesquisadoras nos campos da educação da infância e da educação indígena Guarani no grupo de pesquisa Linguagens, Cultura e Educação - LinCE / CNPq, vinculado ao Programa de Pós-Graduação em Educação da UNISC, com o objetivo de promover a abertura a outros modos de interrogar a educação de crianças pequenas em contextos coletivos a partir da interlocução entre princípio biocêntrico, pensamento ameríndio (MENEZES, 2006) e as fenomenologias da imaginação poética, do corpo operante no mundo e da ação narrativa (RICHTER, 2005).

A tarefa exige fortalecer diálogos, pois, além da projeção de um futuro possível, é necessário enfrentar opções do passado e conviver tanto com concepções redutoras de infância como etapa cronológica de desenvolvimento quanto com modos culturais de educar crianças pequenas em espaços coletivos simplificados pela assistencialização ou pela precoce escolarização. A intenção de resistir a tais concepções de educação das infâncias nos conduz a enfrentar um percurso histórico-político nos modos de perceber e pensar o mundo em que Santos (2000) aponta como subordinação de saberes e conhecimentos estabelecidos pela modernidade ocidental. Aqui, torna-se importante considerar com Streck (2010, p. 21) que "buscar condições para a superação da colonialidade impregnada na ideia de América Latina e 
sua história colonial de mais de quatro séculos" implica compreender a distinção entre os termos "colonialismo" e "colonialidade". Se o primeiro supõe relações geográficas e histórias, o segundo já supõe um processo que "atua como uma matriz subjacente do poder colonial que seguiu existindo depois da independência política" (STRECK, 2010, p. 21). Nessa distinção, a colonialidade dos saberes e o consequente totalitarismo científico (MIGNOLO, 2006, p. 668) configura uma tradição de desconsideração acadêmica pela diversidade nos modos de aprender e conhecer que emergem da ação do corpo no mundo, da espiritualidade, da multidimensionalidade do tempo e das múltiplas dimensões da linguagem. Tal configuração vem desafiando a possibilidade histórica de produzir outras interrogações em torno da educação das crianças em tempos e espaços coletivos.

A precariedade de estudos voltados para outros modos de ser criança, para além da urbana "assistida" ou "escolarizada", evidencia tanto modos hegemônicos de conceber a educação das diferentes infâncias quanto expõe modos antagônicos de promover a formação docente gerando políticas diferenciadas. Se por um lado, as diferenças são necessárias, por outro, torna-se importante potencializar o diálogo para que ambas possam ser pensadas e explicitadas em sua inter-relação ou coexistência. Mesmo esse diálogo estando ainda longe de ser efetivado - seja nas regiões do Vale do Rio Pardo e Vale do Jacuí, seja no país - o movimento para sua conquista pode contribuir para a compreensão da complexidade da sociedade brasileira e o imenso desafio político de seus gestores não apenas para pensar e discutir a expansão das redes públicas de educação infantil, mas também para negociar e garantir políticas públicas integradas em torno do compromisso existencial, intercultural e político com as infâncias brasileiras.

O interesse científico de nos reunirmos encontra-se na proposição de aproximar nossas investigações, misturar os campos como modo de reivindicar outra concepção para a ideia de infância e outras racionalidades para educar crianças em contextos coletivos. Outra racionalidade mais sensível, po(i)ética, que mostre a importância de agregar outras dimensões da linguagem, outras narrativas, outros saberes e outros fazeres que fortaleçam o compromisso com ações educativas e práticas pedagógicas alicerçadas não apenas no cuidado e na atenção à escuta das crianças e suas famílias, mas também em narrativas que nos religuem às nossas heranças radicais. Significa comprometer-se com uma ética da resistência ao lembrar que há outras infâncias possíveis: escolhas políticas inescapáveis. 


\section{FENOMENOLOGIA E PENSAMENTO AMERÍNDIO: CONSTITUINDO ESTRATÉGIAS TEÓRICAS E METODOLÓGICAS NO CAMPO DA EDUCAÇÃO DA INFÂNCIA}

Do encontro entre os estudos desenvolvidos no projeto Dimensão poética das linguagens na educação da infância (2011-2013) e estudos em torno da cosmologia Guarani (MENEZES, 2006; 2009) surge o projeto Infância e Educação Guarani, financiado pela FAPERGS/Edital Pesquisador Gaúcho (2013), com o objetivo de se deter na problemática da educação das crianças Guarani em duas aldeias no interior do Rio Grande do Sul - Estrela Velha (Vale do Rio Pardo) e Salto do Jacuí (Vale do Jacuí).

O projeto, vinculado às linhas de pesquisa Aprendizagem, tecnologias e linguagens na educação e Educação ameríndia, princípio biocêntrico e movimentos sociais, discute o percurso intercultural de implantação de duas escolas diferenciadas nas aldeias Guarani: Escola Estadual Indígena de Ensino Fundamental João Oliveira Karaí em Salto do Jacuí e Escola Estadual Indígena de Ensino Fundamental Karaí Tata Endy Vera Claudio Acosta em Estrela Velha. Nas duas aldeias participam lideranças indígenas, crianças e jovens locais, professores Guarani e não indígenas, diretores da rede Estadual de Educação Karai e Kunhã Karai, estudantes dos cursos de Pedagogia e de Psicologia e pesquisadores do Mestrado em Educação da Universidade de Santa Cruz - UNISC/RS. Juntos, buscamos o diálogo através da escuta do que pensamos e queremos como escola diferenciada em cada aldeia Guarani. A partir do vivido entre nós, nos encontros na aldeia em que almoçamos juntos, compartilhamos o alimento, nos escutamos conversando e convivendo, e de reflexões sustentadas no percurso metodológico que se desenvolve através de uma pesquisa-ação e etnográfica de modo compartilhado e negociado, no qual indígenas e não indígenas vão se constituindo pesquisadores, partindo de um pensar biocêntrico e fenomenológico.

Se a fenomenologia favorece uma coesão entre teorias pautadas pela consideração da existência do corpo no mundo (MERLEAU-PONTY, 1999) como fluxo auto-organizativo e a auto-organização como princípio da complexidade (MORIN, 2011), o pensamento ameríndio contribui com a sensualidade dos corpos, a ambiguidade da linguagem pela consideração da oralidade, do tempo, da memória. A visão biocêntrica e ameríndia permite perceber modos de aprendizagem que não estão pautados pela lógica meramente humana, tendo esta como centro do mundo. Dimensões como a terra, os ciclos rítmicos da natureza, os animais, a mata, o rio, nos fazem viver outros diálogos educativos. Aqui, o pesquisador está implicado naquilo que "quer ver", comprometido com o modo como percebe, pois só podemos perceber o que 
experimentamos na coexistência mundana. Esse caminho tem nos conduzido à mescla inextrincável entre razão e imaginação, real e ficcional, pensamento racional, intuitivo, empírico, técnico e pensamento simbólico, mitológico, mágico, permitindo formular narrativas potentes para enfrentar a complexidade da educação de crianças. O desafio contemporâneo de pensar e realizar projetos educativos com crianças supõe enfrentar a tendência contemporânea de priorizar o treinamento para o mercado, a competição, a preparação de um futuro.

Para Bergamaschi (2005), a interação entre escolas, pesquisadores, acadêmicos e docentes da rede pública tem favorecido a constituição da escola diferenciada Guarani, pois este movimento contempla a reflexão sobre o estar sendo ameríndio que, segundo a autora em suas leituras de Rodolfo Kusch, aponta para um modo de vida indígena que é parte da civilização americana e que, por sua vez, é pouco valorizada e compreendida nos projetos educacionais. Ao pensar a escola diferenciada na aldeia torna-se importante o resgate de outra escuta e outro olhar para o sentido educacional de saberes e modos de pensar ameríndios. Espiritualidade, silêncio, tempo, ludicidade, corporeidade são aspectos fundamentais a serem também respeitados e reconhecidos no contexto dessa escola. Supõe acolher as diferenças, acolher sua autonomia, seus símbolos, valorizar o diálogo intercultural para elaborar currículos e propor aprendizagens, conteúdos e metodologias.

Desde os primeiros encontros na aldeia, os Guarani colocaram-se em uma postura investigativa e curiosa. Em comum acordo com as lideranças das duas aldeias, os indígenas assumem serem também pesquisadores utilizando desenhos, fotos e filmagens como estratégias de construção de significados e disparadores de diálogos entre indígenas e não indígenas. A palavra é um elemento norteador para compreensão do pensamento Guarani no contexto da educação e da formação das escolas indígenas e de trocas interculturais na qual a noção de identidade ameríndia (GEERTZ, 1989) é percebida não como um valor a ser afirmado, mas uma troca a ser vivida. Aos poucos fomos compreendendo que os encontros se sustentavam em "aprendizagens das palavras" que nos faziam produzir sentidos e significados para nossa co-existência e educação. Fomos compreendendo com Melià (2010, p. 42), que a educação Guarani “é uma educação da palavra, pela palavra”, não para aprender e memorizar textos, mas "para escutar as palavras que receberá do alto, geralmente através do sonho, e poder dizê-las". 
O fato de estarmos pesquisando com as crianças na aldeia suscitou, entre os Guarani, a reflexão do quanto elas estão atentas à palavra antiga que escutam dos mais velhos; do quanto elas os fazem lembrar da palavra antiga, como a dança Tangará que é realizada com as crianças para que "não esqueçam os antigos". Temos percebido que estudar as crianças Guarani é também estudar os velhos. Segundo relato do cacique da aldeia de Estrela Velha, "todas as manhãs as crianças vão tomar café com dona Catarina" compartilhando sonhos e memórias, reafirmando que a "aprendizagem vem da memória dos que escutam e vivem. Tem que sentir que sabe, ter vivência... faz sentido no pensamento, no coração, lá no centro do céu..." (MENEZES, 2006). Gradualmente, vamos nos aproximando do sentido da educação das crianças, não como a "infância" descrita pela cultura ocidental, mas como um modo de estar afirmada pelos Guarani, como modo de viver: "Infância é Nhanderekó" - modo de ser, responde Márcio, professor Guarani da escola de Salto do Jacuí quando indagado pelo sentido Guarani de infância.

A infância como Nhanderekó pode ser observada nos desenhos das crianças e jovens da aldeia de Estrela Velha, nos quais observamos o quanto as crianças expressam o tekoá como um ambiente repleto de árvores, rio, sol, opy. Esses desenhos se repetem, como uma memória de um passado não vivido, mas imaginado e escutado. Observamos que a imagem do desenho se faz visível pela escuta, pela palavra. São momentos que representam também espaços reflexivos da criança a partir da íntima relação entre imagem, palavra e natureza.

Essa experiência de convivência permite reafirmar o que conquistamos como concepção de aprendizagem nos estudos em torno da dimensão poética das linguagens ao alcançarmos valores educacionais sustentados em uma estética e uma ética dos tempos lentos, do corpo no mundo, do imagético multisensório, do poder das narrativas ficcionais que revelam diversos modos de ser criança. Assim podemos compreender que os termos infância e criança não são sinônimos. Infância diz respeito às ideias em espaços e tempos constituídos historicamente - conceitos, pré-conceitos, esperanças: sonhos, discursos e expectativas de adultos a partir da criança que foram e que imaginam ter sido, enquanto crianças são simultaneamente únicas e plurais, aqui e agora, compartilhando com adultos uma coexistência comum marcada pela alteridade linguageira entre ambos. Temos infância em várias línguas, em diferentes lugares e culturas, com termos e sentidos diferentes que se modificam a partir de suas raízes históricas, assim como temos crianças, segundo as definições das Diretrizes Curriculares Nacionais para a Educação Infantil (CNE/SEB n5/2009), como um 
sujeito histórico e de direitos que, nas interações, relações e práticas cotidianas que vivencia, constrói sua identidade pessoal e coletiva, brinca, imagina, fantasia, deseja, aprende, observa, experimenta, narra, questiona e constrói sentidos sobre a natureza e a sociedade, produzindo cultura. (BRASIL, 2009, p. 12)

Neste sentido, ser criança é viver o devir da experiência de aprender, com outras crianças e adultos, a fantasiar, brincar, narrar, explorar, interrogar, enfim, aprender a pensar com outros. Todos nós adultos fomos crianças, passamos também por processos de viver o devir mundano que somos hoje. Não como "passagem de o que não é ao que sim será", pois "o que será já não é criança” (SKLIAR, 2012, p. 17), mas como alteridade de nós mesmos. Nesse sentido, o tempo da criança é um tempo radical na vida de todos. Para Fronckowiak e Richter (2005, p. 05), a infância se constitui porque "o corpo tem história" porque emerge de começos e repertórios de mundo, vivências experimentadas sempre pela primeira vez. Ações estas que são as linguagens, que se realizam através de ações entre a criança e o mundo, o corpo, as materialidades. Nesse sentido, sempre precisamos dos outros para existir e viver uma história mundana singular.

\section{CONTRIBUIÇÃo DO PENSAMENTO AMERÍNDIO PARA OUTRO MODO DE ABORDAR A RELAÇÃO ENTRE INFÂNCIAS, EDUCAÇÃO E ESCOLARIZAÇÃO}

O desejo dos Guaranis pela escola dos juruás e o próprio desejo de assumir nossas alteridades vem promovendo a singularidade de um processo firme, atento e fluido que não pretende engessar a forma escolar a ser instalada e sistematizada, mas antes favorecer um contexto educacional a ser vivido naquilo que acontece e naquilo que é idealizado, pois tecido pelo que permanece e pelo que se altera. Nesse sentido, compartilhamos com Viveiros de Castro (2002) que

uma cultura não é um sistema de crenças, mas antes - já que deve ser algo - um conjunto de estruturações potenciais da experiência, capaz de suportar conteúdos tradicionais variados e de absorver novos: ela é um dispositivo culturante ou constituinte de processamento de crenças. (VIVEIROS DE CASTRO, 2002, p. 209)

Na perspectiva de Viveiros de Castro (2002a, p. 130), não se trata de tomar a relação dos indígenas com seu discurso em termos psicologistas da crença, nem nos termos lógicos do valor de verdade - não se trata de tomar esse discurso como uma opinião ou um conjunto de proposições, pois não concebe a crença como um "estado mental" e sim como um pensamento diante do que há a conhecer. Para o antropólogo brasileiro, a crença diz respeito ao 
pensamento como "atividade e um efeito da relação" entre quem pensa e o que é pensado, entre o que é pensado e o que remete contingentemente aos estados de coisas, enfim uma "convenção de interpretação", uma prática de sentido a qual permite pensar o outro pensamento como "atualização de virtualidades insuspeitas do pensar" (VIVEIROS DE CASTRO, 2002a, p. 129). Assim, no encontro intercultural entre indígenas e não indígenas não cabe explicar, crer ou descrer o mundo educacional do outro, mas multiplicar modos de educar.

O interesse dos Guarani pela implantação da escola diferenciada nas duas aldeias é o encontro com esse "dispositivo culturante", apontado por Viveiros de Castro (2002) como um encontro com um sistema educacional que o altera e, nos termos de Kusch (1999), restabelece e melhora sua condição mas sem adulterá-la. O encontro entre os Guarani e os juruás para pensar e realizar uma escola diferenciada implica enfrentar a tensão transitória entre a ordem e o caos, ou na abordagem fenomenológica de Kusch (1999), entre o ser que prevalece no modo ocidental de pensar e viver na cidade - e o terrível medo do imprevisto - e o modo próprio de um pensamento ameríndio que se mantém no mero estar, ou seja, no mero viver no terreno da comunidade e que consiste em "estar firmemente aqui" reconhecendo a natureza como ira de deus ou como temor diante da tormenta, o raio e o trovão (KUSCH, 1999).

A escola diferenciada situa-se assim em um tempo e um espaço entre as cosmovisões ameríndia e ocidental europeia. As discussões que temos tido em torno da escola diferenciada nos faz aprofundar as formas distintas de compreensão de mundo e de culturas indígenas e europeias, as quais possuem concepções diversas acerca da linguagem, do ambiente, da educação, da saúde, do modo de viver e de conceber a vida. Concepções também diferenciadas de infância e de criança.

A compreensão de interculturalidade como diálogo entre interlocutores no qual tende a se interpor o modo cultural - cosmologias - encarnados em cada um é dada a partir da distinção estabelecida por Kusch (1978, p. 136) entre "o cultural” como processo e "a cultura" como institucionalização. Kusch (1978, p. 135-137), ao afirmar os processos culturais como dinâmica existencial - uma estratégia para viver e habitar o mundo (KUSCH, 2012) - os concebe como "o baluarte simbólico no qual cada um se refugia para defender a significação de sua existência" (KUSCH, 1978, p. 14). Uma defesa que permita enfrentar o desconhecido e que sem a qual não se teria ou não se encontraria elementos para enfrentar uma novidade incompreensível. Portanto, contra a ideia corrente de cultura apenas como "acervo espiritual" ou "totalidade rígida" que determinado grupo oferece a cada um como tradição, Kusch (1978, 
p. 14) a aponta como possibilidade de alcançar um "domicílio existencial”. Ou seja, uma zona de familiaridade na qual possamos nos sentir seguros para significar o que nos acontece e enfrentar interlocutores de tal modo

que poderia ser preenchida com elementos não tradicionais, inclusive com referências simbólicas encontradas no momento, que estabelecem uma diferenciação em relação ao interlocutor, e que adquirem no momento do diálogo o valor de padrões culturais com os quais se define a si mesmo frente ao outro. (KUSCH, 1978, p. 14).

A partir dessa concepção, Kusch (1978, p. 135) propõe a substituição de uma perspectiva compartimentada do humano, na qual cultura e educação - e por extensão infância e criança - têm sentidos estabelecidos pelo ser enquanto um efêmero "isto é" que se dilui em um sendo pela consideração dos processos culturais e educacionais em seu valor de ato, ou seja, não pelo que representam, mas pela margem de instalação desde um estar (KUSCH, 1978). No pensamento fenomenológico de Kusch (1999), o ser não pode dar-se sem o estar, porque é neste último que a vida emerge com densidade maior que naquele. O ser surge do estar, pois é do estar que o ser extrai os elementos para sua dinâmica. Nesse sentido filosófico, ser e estar não se excluem. Não há controvérsia entre ambos e sim uma conjunção que se expressaria em um estar sendo no qual o gerúndio de ser não emerge segregado, mas instalado no estar apontando "nossa variante de ser em meio do abismo inseguro de nosso estar" (KUSCH, 1978, p. 99).

Essa compreensão torna-se potente para pensar outra concepção de infância que aponta para "um estado, uma condição, uma duplicação que os adultos realizam sobre as crianças" (SKLIAR, 2012, p. 16). Se pensarmos com Skliar (2012, p. 16) que "as crianças tem rostos, idades, semblantes, gestos, ações, dias, noites, sonhos, pesadelos, pernas, nomes", as imagens ou narrativas de infância e de criança não coincidem e quando tentamos submetê-las a determinada infância algo se perde (SKLIAR, 2012). Por isso, para Dahlberg, Moss e Pence (2003, p. 71), "não há uma infância natural nem universal, e nem uma criança natural ou universal, mas muitas infâncias e crianças”. Nesse pressuposto, as infâncias emergem sempre de concepções situadas em relação ao tempo, ao local e à cultura, sendo que o modo como são compreendidas dizem respeito a entendimentos e narrativas constituídos coletivamente. As crianças, por sua vez, estão entre nós, são ativas no seu contexto de vida coletiva, agindo no mundo em que vivem, e isso significa que as crianças não somente estão incluídas, mas vivem em relacionamento ativo no coletivo social, incorporando o mundo no qual vivem, 
influenciando este mundo e construindo significados a partir dele (DAHLBERG, MOSS e PENCE, 2003).

A questão, para Cohn (2005), deixa de ser apenas como e quando a cultura é transmitida, mas como a criança formula um sentido ao mundo que a rodeia. A diferença entre as crianças e os adultos "não é quantitativa, mas qualitativa; a criança não sabe menos, sabe outra coisa" (COHN, 2009, p. 33), outra lógica linguageira. Assim, não é transformar este mundo em dois mundos diferentes, mas sim, considerar que ele pode ser interpretado de modos diferentes.

Tal afirmação implica reconhecer que "as crianças não são apenas produzidas pelas culturas mas também produtoras de cultura" (COHN, 2005, p. 35). Reconhecimento que não implica afirmar a existência de uma cultura infantil. Seria radicalizar a cisão entre o mundo dos adultos e o das crianças, ou seja, seria universalizar e, assim, negar as particularidades socioculturais. Tal compreensão teria o custo de uma nova e irredutível cisão entre crianças e adultos, pois seria tornar esses mundos incomunicáveis. Antes, trata-se de resistir à generalizada concepção de infância como momento ou etapa estanque da vida, momento a ser superado pelo ser adulto. Aqui, a infância não termina, pois deixa marcas, permanece e habita os percursos ao longo da vida, pode ser transformada porque pode ser revivida e narrada.

Gaston Bachelard (1988) aponta que a infância permanece em nós como um princípio de vida profunda sempre relacionada à possibilidade de recomeçar quando revivificada por entusiasmos que duram em nós como uma intensidade, uma presença, um jeito de ser e estar no mundo. A infância permanece como uma reserva de sonhos, de tristezas, de entusiasmos. Para Richter (2005, p. 193), trata-se de um "acordo temporal que nos vincula às primeiras aprendizagens da infância, o mundo da primeira vez". Com Bachelard (1988), podemos compreender que infância

não é uma coisa que morre em nós e seca uma vez cumprido o seu ciclo. Não é uma
lembrança. É o mais vivo dos tesouros, e continua a nos enriquecer sem que o
saibamos... Ai de quem não pode se lembrar de sua infância, reabsorvê-la em si
mesmo, como um corpo no seu próprio corpo, um sangue novo no sangue velho:
está morto desde que ela o deixou. (BACHELARD, 1988, p. 130)

Cada criança é um modo particular de estar sendo no mundo vivido, experimentadoo com o corpo sensível brincante que memoriza e se transforma através de uma história, de um cheiro, de um sabor, de uma narrativa, enfim, daquilo que realmente a marca e que retorna em lembranças, em sensações, em imagens que permanece no corpo linguageiro. Nesse sentido, aprender a imaginar, narrar, brincar, faz parte deste processo de sensível. O corpo 
interage e se constitui no tempo como condição de estabelecer relações com o vivido. Se compreendermos a infância como discurso histórico composto por adultos a partir de expectativas de como deve ser a vida, ambos os termos apontam que ser criança não implica a experiência de uma única infância.

O currículo e o desempenho docente caminham juntos. Torna-se então importante considerar nos processos de escolarização as ações das crianças, agregando-as nas práticas pedagógicas, articulando seus saberes e suas experiências, procurando promover e estabelecer no cotidiano da escola a continuidade de processos, de começos, de uma escolarização que favorece, no encontro entre adultos e crianças, a constituição de repertórios sustentados em relações e ações que ocorrem no corpo através de interações que respeitem o contexto mundano no qual ambos estão imersos.

Esse espaço educacional exige preparo e disponibilidade dos professores para com as diferentes dimensões da linguagem e as experiências provocativas na interlocução com as crianças e a famílias favorecendo assim uma construção de currículo na convivência coletiva. Neste sentido, os Guaranis zelam pela continuidade de suas origens, de suas culturas, ensinando o que sabem, transmitindo às crianças na convivência mesma de juntos cantarem, dançarem, brincarem, participarem de ritos e narrativas. Segundo os indígenas de ambas as aldeias, trata-se de não esquecerem, ou seja “aquilo que sabe e não quer esquecer" (Diário de campo, 2013). Nas palavras do professor indígena da aldeia de Salto do Jacuí,

antigamente os avós, os bisavós viviam assim, sem se preocupar. Essa cultura maravilhosa se repassava e davam continuidade ao mesmo. Hoje as tecnologias, o face está dominando, as crianças, não querem mais dançar, uma cultura milenar que esta sendo perdida pelo mundo virtual. (Diário de campo, 2013)

Hoje, o tempo do aqui e do agora é o tempo que as crianças vivenciam intensamente. O humano é devir que chega ao mundo transformando e sendo transformado, de acordo com a pluralidade de experiências de linguagem. Tempo no qual a potência de fazer escolhas constitui sua história no coletivo. Acelerar experiências de pensamento em torno de respostas rápidas é exigir da criança a experiência de um tempo vivido por adultos. Porém, a criança vive o tempo presente em ato, "não há antes, durante e depois naquilo em que as crianças fazem" (SKLIAR, 2012, p. 17). Esta temporalidade de estar sendo, de vivenciar fazeres em ato, explorando intensamente sem preocupação o tempo da duração, implica compreender com o poeta Paul Valéry (1999, p. 185) que "a obra do espírito só existe como ato" ou com o 
filósofo Walter Kohan (2004, p. 3) que "no fundo, o tempo é apenas um limite entre o que já foi e o que ainda não é”.

O encontro entre o projeto Dimensão poética das linguagens na educação da infância (2011-2013) e Infância e educação Guarani (2013-2015) vem permitindo ao grupo sustentar a intencionalidade pedagógica de favorecer, nos processos iniciais de escolarização, experiências lúdicas - brincantes - que considerem a complexidade vital de aprender o poder inventivo da linguagem, desde a infância a partir de um pensamento pedagógico valorado tanto pela razão quanto pela imaginação. A questão - ou inquietação - não é privilegiar um modo em detrimento de outro, pois seria sacrificar um e outro (BACHELARD, 2004). Nada mais complexo que a experiência de brincar com as dimensões da linguagem - ser brincante $d a$ e na linguagem - pois pleno da humanidade de cada dia ao dizer respeito porque é experiência que emerge de ações sem causa ensinante: é apreender-se; é conquista de si.

Nessa perspectiva, o desafio educacional - sempre político - está em perseguir a ultrapassagem das desigualdades históricas também no que diz respeito à especificidade da educação das crianças em tempos e espaços coletivos. Tal ultrapassagem exige enfrentar a lógica da colonialidade que, para Streck, Adams e Moretti (2010, p. 22), é hegemônica e “expressa-se pela distribuição desigual da riqueza, mas igualmente pelo domínio geopolítico da epistemologia". Para os autores, enfrentar a colonialidade pedagógica supõe "aprender com o espírito que produziu culturas e conhecimentos, mas sem repetir e copiar servilmente os frutos de culturas do norte. Compreende-se aqui o sul (países do sul, ótica do sul) como metáfora do sofrimento humano causado pelo colonialismo capitalista" (STRECK; ADAMS; MORETTI, 2010, p. 23). Para Boaventura de Sousa Santos (2006),

o Norte não é inteligível fora da relação com o Sul, tal como o conhecimento tradicional não é inteligível sem a relação com o conhecimento científico ou a mulher sem o homem. Assim, não é admissível que qualquer das partes tenha vida própria para além da que lhe é conferida pela relação dicotómica e muito menos que possa, além de parte, ser outra totalidade. (SANTOS, 2006, p. 783)

O enfrentamento da lógica da colonialidade não supõe negar a herança da racionalidade moderna, mas reconhecer as diferenças também nos modos de viver - aprender e conhecer - questionando tanto o modelo escolar hegemônico quanto a ideia redutora de infância no singular para promover abertura a outros modos de conceber a educação de crianças pequenas: assumindo o seu protagonismo nas transformações da vida coletiva a partir da valorização da diversidade cultural das infâncias. 


\section{REFERÊNCIAS}

BACHELARD, G. Ensaio sobre o conhecimento aproximado. Rio de Janeiro: Contraponto, 2004.

BACHELARD, G. A poética do devaneio. São Paulo: Martins Fontes, 1988.

BERGAMASCHI, M. A. NHEMBÓ E! Enquanto o encanto permanece! Processos e práticas de escolarização nas aldeias Guarani. Porto Alegre, 2005. 273 p. Tese (Doutorado), Programa de Pós-Graduação em Educação, Universidade Federal do Rio Grande do Sul, 2005.

BRASIL. Ministério da Educação. Conselho Nacional de Educação. Resolução CNE/CEB no 5, de 17 de dezembro de 2009. Fixa as Diretrizes Curriculares Nacionais para a Educação Infantil. Brasília: CNE, 2009. Disponível em: http://portal.mec.gov.br/index.php?option=com_docman\&view=download\&alias=2298rceb005-09\&category_slug=dezembro-2009-pdf\&Itemid=30192........ Acesso em: 21 maio 2013.

COHN, C. Antropologia da criança. Rio de Janeiro: Jorge Zahar, 2005.

DAHLBERG, G.; MOSS, P.; PENCE, A. R. Qualidade na educação da primeira infância: perspectivas pós-modernas. Porto Alegre: Artmed, 2003.

FRONCKOWIAK, Â.; RICHTER, S. A dimensão poética da aprendizagem na infância. Reflexão e Ação, Santa Cruz do Sul, n. 1, v. 13, p. 91-104, jan./ jun. 2005.

GEERTZ, C. A interpretação das culturas. Rio de Janeiro: Livros Técnicos e Científicos, 1989.

KOHAN, W. O. Apontamentos para uma (nova) filosofia e uma (também nova) educação da infância. In: $27^{a}$ Reunião Anual da ANPEd, 2004, Caxambú, MG. Sociedade, Democracia e Educação: Qual Universidade? Rio de Janeiro, RJ: UERJ - CEFET, 2004.

KUSCH, R. América Profunda. Buenos Aires: Biblos, 1999.

KUSCH, R. Esbozo de una antropologia filosofica americana. Buenos Aires: Ediciones Castañeda, 1978.

KUSCH, R. Geocultura del hombre americano. Rosario: Fundación A. Ross, 2012.

MELIÀ, B. Educação guarani segundo os Guarani. In: STRECK, D. R. (Org.). Fontes da pedagogia latino americana: uma antologia. Belo Horizonte: Autêntica , 2010. p. 37-53.

MENEZES, A. L. T. de. A alegria do corpo-espírito saudável: ritos de aprendizagem guarani. Porto Alegre, 2006. 265 p. Tese (Doutorado), Programa de Pós-Graduação em Educação, Universidade Federal do Rio Grande do Sul, 2006.

MENEZES, A L. T. de; BERGAMASCHI, M. A. Educação ameríndia: a dança e a escola Guarani. Santa Cruz do Sul: EDUNISC, 2009. 
MERLEAU-PONTY, M. Fenomenologia da percepção. Trad. Carlos Alberto Ribeiro de Moura. 2. ed. São Paulo: Martins Fontes, 1999.

MIGNOLO, W. D. Os esplendores e as misérias da "ciência": colonialidade, geopolítica do conhecimento e pluri-versalidade epistêmica. In: SANTOS, B. de S. (Org.). Conhecimento prudente para uma vida decente: um discurso sobre as ciências revisitado. São Paulo: Cortez, 2006. p. 667-709.

MORIN, E. Introdução ao pensamento complexo. Trad. Eliane Lisboa. 4. ed. Porto Alegre, Sulina, 2011.

RICHTER, S. R. S. A dimensão ficcional da arte na educação da infância. Porto Alegre, 2005. 290 p. Tese (Doutorado). Programa de Pós-Graduação em Educação, Universidade Federal do Rio Grande do Sul, 2005.

SANTOS, B. de S. A crítica da razão indolente: contra o desperdício da experiência. In: Para um novo senso comum - a ciência, o direito e a política na transição paradigmática. São Paulo: Cortez, 2000.

SANTOS, B. de S. (Org.). Conhecimento prudente para uma vida decente: um discurso sobre as ciências revisitado. São Paulo: Cortez, 2006.

SKLIAR, C.. As interrupções no corpo, a atenção, a ficção e a linguagem da infância. In: XAVIER, I. M.; KOHAN, W. O. (Orgs.). Filosofar: aprender e ensinar. Belo Horizonte: Autêntica, 2012. p. 15-24.

STRECK, D. (Org.). Fontes da pedagogia latino-americana: uma antologia. Belo Horizonte: Autêntica, 2010.

VALÈRY, P. Primeira aula do curso de poética. In: . Variedades. São Paulo: Iluminuras, 1999.

VICENT, G.; LAHIRE, B.; THIN, D. Sobre a história e a teoria da forma escolar. Educação em Revista [online], Minas Gerais, n. 33, p. 07-47, 2001.

VIVEIROS DE CASTRO, E. A inconstância da alma selvagem e outros ensaios de antropologia. São Paulo: Cosac \& Naify, 2002.

VIVEIROS DE CASTRO, E. O nativo relativo. Mana [online], Rio de Janeiro, n. 1, v. 8, p. 113-148, abr. 2002.

ZINN, T.; RICHTER, S. R. S. Rodas poéticas e ludicidade das linguagens na Educação Infantil. XXV Salão de Iniciação Científica da UFRGS. Porto Alegre, Universidade Federal do Rio Grande do Sul, 2013. (Resumo expandido). 